\title{
Long-Term Cost Performance of Corrosion-Resistant Reinforcements in Structural Concrete
}

\author{
Adel Younis \\ adel.younis@qu.edu.qa \\ Department of Civil and Architectural Engineering, Qatar University, Doha, Qatar \\ Usama Ebead \\ uebead@qu.edu.qa \\ Department of Civil and Architectural Engineering, Qatar University, Doha, Qatar
}

\begin{abstract}
Corrosion, which leads to the premature deterioration of reinforced concrete (RC) structures, is increasingly an issue of global concern. Accordingly, corrosion-resistant materials have emerged as alternative reinforcement solutions in concrete structures. Yet, the high initial cost of such materials may mitigate their potential use. This paper reports on the results of two life-cycle-cost-analysis (LCCA) studies that aim at verifying the long-term cost performance of corrosion-resistant reinforcements in structural concrete. The first study conducted a 100-year-based LCCA study to evaluate the relative cost savings of structural concrete that combines seawater, recycled coarse aggregates, and glass fiber-reinforced polymer (GFRP) reinforcement in high-rise buildings as compared to a traditional reinforced concrete (i.e., freshwater-mixed, natural-aggregate, black-steelreinforced). In the second study, a life-cycle-cost comparison was established among four reinforcement alternatives, viz., conventional steel, epoxy-coated steel, stainless steel, and GFRP for a RC water chlorination tank considering a 100-year study period. The results of these two studies suggest that the use of corrosion-resistant reinforcement (especially GFRP) in structural concrete may potentially lead to significant cost savings in the long term: the net present cost of GFRP-RC structures was generally $40-50 \%$ lower than that reinforced with black steel.
\end{abstract}

Keywords: Sustainably; Alternative materials; Reinforced concrete; Life-cycle costing

\section{INTRODUCTION}

Nowadays, there has been a growing interest among researchers to achieve sustainability goals in reinforced concrete (RC) structures, mostly by introducing alternative "greener" materials for construction and repair. Steel reinforcement corrosion is deemed a significant factor hindering sustainable development by causing premature deterioration of reinforced concrete structures. In an attempt to address this issue, non-corrosive materials (e.g., glass fiber-reinforced polymer (GFRP) and stainless steel) have been suggested by researchers as alternative reinforcement solutions for concrete. However, the higher initial cost of such materials (compared to that of the conventional black steel) imposes a long-term economic investigation to evaluate their actual cost performance during an RC structure's service life. In view of that, the current paper presents two studies on the long-term cost performance of corrosion-resistant reinforcements in structural concrete. In Study 1 (Younis et al., 2018), a life cycle cost 
analysis (LCCA) was performed to verify the cost savings associated with using seawater, recycled coarse aggregates (RCA), and GFRP reinforcement in structural concrete. For this, two design alternatives were compared for a high-rise building, namely, RC1 that represents the conventional design (i.e., freshwater-mixed natural-aggregate concrete with black steel reinforcement), and RC2 (seawater-mixed, recycled-aggregate, GFRPreinforced concrete). Likewise, Study 2 (Younis et al., 2020) compared the long-term cost performance among four reinforcing materials (viz., black/epoxy-coated/stainless steels and GFRP) for a concrete water chlorination tank using LCCA.

\section{METHODOLOGY}

Typically, the life cycle cost model included 4 main elements (Figure 1), namely, material cost, construction cost, maintenance/repair cost, and end-of-life/disposal cost. Further details and assumptions regarding each component of the cost model can be found in (Younis et al., 2018, 2020). Material characterization and structural design details of the buildings considered can be found in (Foraboschi et al., 2014)of the components, per net rentable area for Study 1 and in (Mohamed \& Benmokrane, 2014)but also to durability and crack control. This paper presents the design procedures, construction details, leakage testing, and monitoring results for the world's first RC water chlorination tank totally reinforced with glass-fiber-reinforced polymer (GFRP for Study 2. Unit costs used in LCCA calculations are provided in (Younis et al., 2018) for Study 1 and in (Younis et al., 2020) for Study 2. All costs were allocated for a functional unit of $1 \mathrm{~m}^{2}$ of the building floor in Study 1, whereas the functional unit considered in Study 2 was $1 \mathrm{~m}^{3}$ of the water tank capacity. Life-365 software (Ehlen et al., 2009) was used to predict the repair activity timing as well as the service life of RC structures. A life cycle period of 100 years was considered in both studies, at which end, it was assumed that the structure would be demolished regardless of any potential remaining service life. Finally, the Net Present Cost (NPC) was obtained as the sum of all partial costs incurred over the entire life cycle, not overlooking the opportunity value of time, calculated as follows (ISO 15686-5, 2008):

$$
N P C=\sum_{t=0}^{T} \frac{C_{t}}{(1+r)^{t}}
$$

where $t$ is the time (in years), $T$ is the analysis period, is the cost incurred at year $t$, and $r$ is the real discount rate.

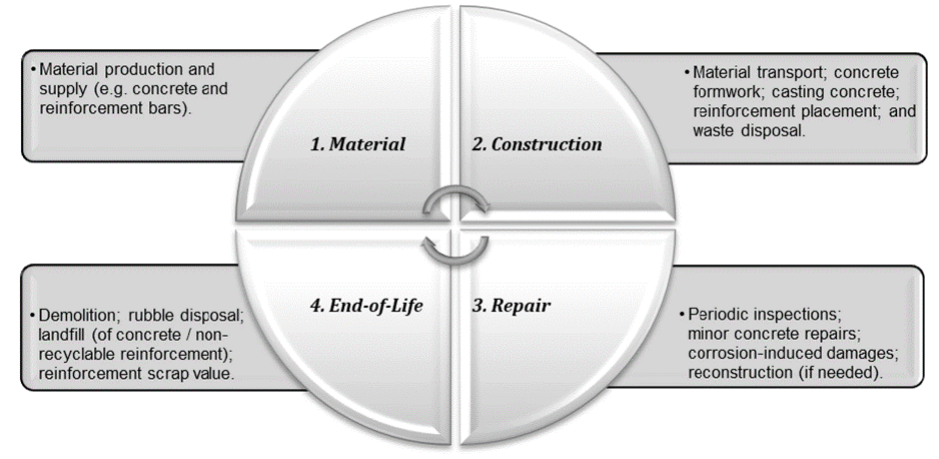

Figure 1: Components of the Life Cycle Cost Model (Younis et al., 2020). 


\section{RESULTS AND DISCUSSIONS}

Table 1 presents the LCCA outcomes for Study 1. As shown in the table, the proposed design alternative RC2 had a $50 \%$ lower NPC compared to that of the conventional design ( $\mathrm{RC} 1$ ), indicating the economic advantage of the former in the long term. Previous cost studies on GFRP reinforcement generally show an agreement with the results herein (Cadenazzi et al., 2019). It is to be noted that the alternative materials in concrete mixtures (i.e., seawater and RCA) ultimately had little-to-no effect on the long-term cost performance of $\mathrm{RC}$ structures. The life-cycle-cost difference between the two design alternatives ( $\mathrm{RC} 1$ and $\mathrm{RC} 2$ ) was actually realized with altering reinforcement material. Yet, it is emphasized that these findings are solely realized from the financial perspective of the building's owner: the use of seawater and/or RCA in concrete mixtures actually has an environmental significance that reaches far beyond (Arosio et al., 2019; Hossain et al., 2016).

Table 1: LCCA results of Study 1.

\begin{tabular}{|c|c|c|c|c|c|c|}
\hline \multirow{2}{*}{$\begin{array}{c}\text { Design } \\
\text { alternative }\end{array}$} & \multicolumn{5}{|c|}{ Present Costs $\left(\$ / \mathrm{m}^{2}\right)$} & \multirow{2}{*}{$\begin{array}{c}\text { NPC } \\
\left(\$ / \mathbf{m}^{2} \text { floor area }\right)\end{array}$} \\
\hline & Material & Construction & Repair & Reconstruction & End-of-life & \\
\hline RC1 & 90 & 135 & 183.9 & 230.7 & 50.8 & 690.4 \\
\hline RC2 & 174 & 108 & - & - & 54.3 & 336.3 \\
\hline
\end{tabular}

Figure 2 summarizes the LCCA results for Study 2. As shown in the figure, epoxycoated and stainless steel reinforcements had NPC values $11 \%$ and $25 \%$ less than that of the conventional steel, respectively. GFRP reinforcement showed the most saving potential, with a $43 \%$ less NPC compared to conventional steel. Evidently, the higher initial cost associated with corrosion-resistant reinforcements may be recouped in the long term as a result of reducing repair costs (Figure 2) and extending service lives of $\mathrm{RC}$ structures. These results are in conformity with previous research studies concerning the cost effectiveness of corrosion-resistant reinforcements (Grace et al., 2012; Mistry et al., 2016).

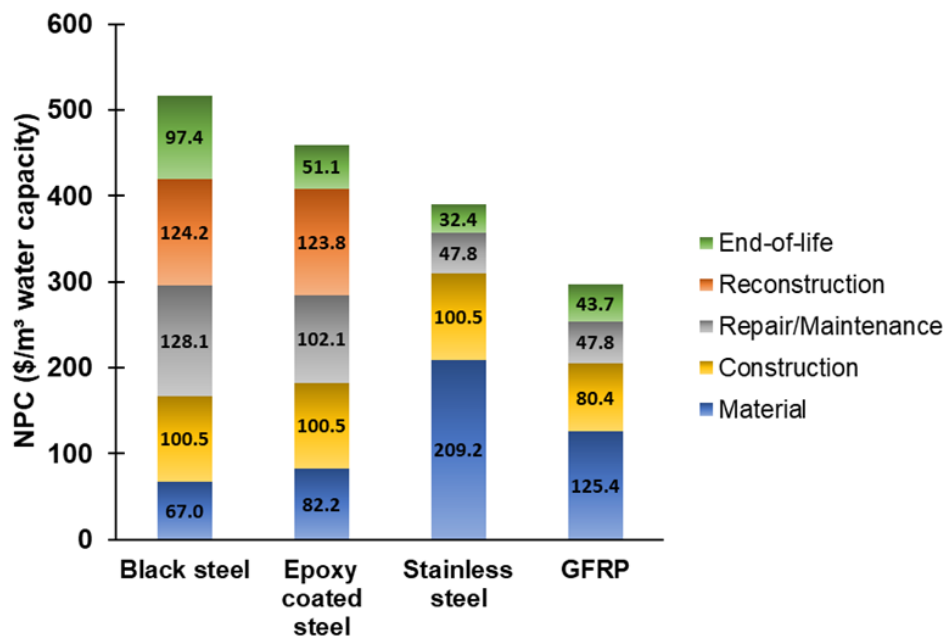

Figure 2: Summary of LCCA results for Study 2 (Younis et al., 2020). 


\section{CONCLUSION}

This paper reports two LCCA studies pertaining to the economic viability of corrosionresistant reinforcement in structural concrete. In Study 1, a potential long-term cost saving of $\sim 50 \%$ was determined for a high-rise RC building when combining seawater, RCA, and GFRP reinforcement in structural concrete (compared to a conventional RC design): the reinforcement material was actually the relevant factor in realizing the cost difference between the two design alternatives. Study 2 had more focus on the application of corrosion-resistant reinforcements in concrete structures: a comparative life-cycle cost analysis was performed to verify the economic viability of using epoxycoated steel, stainless steel, and GFRP in lieu of black steel to reinforce a concrete water chlorination tank. The life cycle cost obtained for epoxy-coated steel, stainless steel, and GFRP reinforcements was approximately 11,25 , and $43 \%$ lower than that of the conventional steel. Nonetheless, the findings achieved herein are only based on the assumptions, the data, and the methods that are specific to the case of these two studies. Future studies are encouraged to enrich the archival literature with more data concerning the cost implications of using alternative materials in RC structures.

\section{ACKNOWLEDGMENT}

The authors would like to acknowledge the fund received by the NPRP grant \# NPRP 9-110-2-052 from Qatar National Research Fund (a member of Qatar Foundation). The findings of this study are solely the responsibility of the authors.

\section{REFERENCES}

Arosio, V., Arrigoni, A. \& Dotelli, G. (2019). Reducing water footprint of building sector: concrete with seawater and marine aggregates. IOP Conference Series: Earth and Environmental Science, IOP Publishing, 323, 12127.

Cadenazzi, T., Dotelli, G., Rossini, M., Nolan, S. \& Nanni, A. (2019). Life-cycle cost and lifecycle assessment analysis at the design stage of a fiber-reinforced polymer-reinforced concrete bridge in Florida. Advances in Civil Engineering Materials, 8(2), 20180113.

Ehlen, M. A., Thomas, M. D. A. \& Bentz, E. C. (2009). Life-365 service life prediction model TM Version 2.0. Concrete International, 31(05), 41-46.

Foraboschi, P., Mercanzin, M. \& Trabucco, D. (2014). Sustainable structural design of tall buildings based on embodied energy. Energy and Buildings, 68, 254-269.

Grace, N. F., Jensen, E. A., Eamon, C. D. \& Shi, X. (2012). Life-cycle cost analysis of carbon fiber-reinforced polymer reinforced concrete bridges. ACI Structural Journal, 109(5), 697704.

Hossain, M. U., Poon, C. S., Lo, I. M. C. \& Cheng, J. C. P. (2016). Comparative environmental evaluation of aggregate production from recycled waste materials and virgin sources by LCA. Resources, Conservation and Recycling, 109, 67-77.

ISO 15686-5. (2008). Buildings and constructed assets-Service-life planning-Part 5: Life-cycle costing. International Organization for Standardization.

Mistry, M., Koffler, C. \& Wong, S. (2016). LCA and LCC of the world's longest pier: A case study on nickel-containing stainless steel rebar. International Journal of Life Cycle Assessment, $21(11), 1637-1644$. 
Mohamed, H. M. \& Benmokrane, B. (2014). Design and performance of reinforced concrete water chlorination tank totally reinforced with GFRP bars: Case study. Journal of Composites for Construction, 18(1), 05013001.

Younis, A., Ebead, U. \& Judd, S. (2018). Life cycle cost analysis of structural concrete using seawater, recycled concrete aggregate, and GFRP reinforcement. Construction and Building Materials, Elsevier, 175, 152-160.

Younis, A., Ebead, U., Suraneni, P. \& Nanni, A. (2020). Cost effectiveness of reinforcement alternatives for a concrete water chlorination tank. Journal of Building Engineering, Elsevier Ltd, 27, 100992. 